\title{
Piper Nigrum Extract as an Environmentally-Safe Inhibitor for the Prevention of Mild Steel in 1.5 M Nitric Acid Medium
}

\author{
N. Balamurugapandian* \\ Department of Chemistry, Madras Institute of Technology, Anna University, Chennai-600044, \\ Tamil Nadu, India
}

Received 23 July 2020, accepted in final revised form 7 October 2020

\begin{abstract}
Piper nigrum has extensively explored for its biological properties and its bioactive phytocompounds. The corrosion prevention of mild steel by Piper nigrum extract (black pepper) using $1.5 \mathrm{M}$ nitric acid medium was examined by the weight-loss method, scanning electron microscope (SEM) examination. The consequences of the study reveal that the dissimilar concentrations of extract prevent mild steel corrosion in acidic medium. The Inhibition efficiency of the extract is found to vary with concentration, temperature, and time of immersion. The inhibition efficiency of the extract was directly proportional to the concentration but inversely proportional to the temperature. Scanning electron microscope experiments exhibit the adsorption of the inhibitory properties of black pepper extract on the surface of the mild steel and show the evidence for the protection of Mild steel by the eco-friendly inhibitor. FTIR values also show evidence for the inhibition of Mild Steel.
\end{abstract}

Keywords: Black pepper; Mild steel; Corrosion; Inhibition efficiency.

(C) 2021 JSR Publications. ISSN: 2070-0237 (Print); 2070-0245 (Online). All rights reserved. doi: http://dx.doi.org/10.3329/jsr.v13i1.48353

J. Sci. Res. 13 (1), 237-242 (2021)

\section{Introduction}

It is known that corrosion of metallic structures has a major impact on the wealth of our country, including infrastructures, transportation, utilities, production and manufacturing, and government. It is the gradual destruction of materials with their environment by chemical and electrochemical reactions [1]. Rusting, the formation of iron oxides is an important illustration of electrochemical corrosion. Characteristically, this type of damage produces oxides or salts of the unique metal and results in distinctive orange coloration. Corrosion can also occur in materials other than metals such as ceramics or polymers, even though in this context, the term "degradation" is more common. Corrosion degrades the valuable properties of materials and structures, including strength, appearance, and permeability of liquids and gases. The corrosion of metal can be prohibited by using

Corresponding author: nbmpandian@mitindia.edu 
inhibitors [2]. For that, the organic inhibitors are mostly used for the prevention of corrosion due to their toxicity. However organic inhibitors influence the environment very strongly. Various investigations have in current times been made into the corrosion inhibiting properties of natural products of plant origin and have been found to usually show good inhibition efficiencies [3]. First and foremost, the influence of this field of research is due to the fact that natural products are environmentally responsive and ecologically satisfactory. The yield of these natural products in addition to the corrosion inhibition ability of the plant extracts vary widely depending on the part of the plant and its location.

The following are the bioactive compounds present in black pepper:<smiles>O=C(/C=C/C=C/c1ccc2c(c1)OCO2)N1CCCCC1</smiles>

(2E,4E)-5-(2H-1,3-benzodioxol-5-yl)-1-(piperidin-1-yl)penta-2,4-dien-1-one<smiles>O=C(/C=C/CCc1ccc2c(c1)OCO2)N1CCCCC1</smiles>

(2E)-5-(2H-1.3-benzodioxol-5-vl)-1-(piperidin-1-vl)pent-2-en-1-one<smiles>O=C(/C=C/C=C/C=C/c1ccc2c(c1)OCO2)N1CCCCC1</smiles>

(2E.4E.6E)-7-(2H-1.3-benzodioxol-5-vl)-1-(piperidin-1-vl)hepta-2.4.6-trien-1-one<smiles>O=C(/C=C/C=C/c1ccc2c(c1)OCO2)N1CCCC1</smiles>

(2E,4E)-5-(2H-1,3-benzodioxol-5-yl)-1-(pyrrolidin-1-yl)penta-2,4-dien-1-one<smiles>CC(C)CNC(=O)/C=C/C=C/c1ccc2c(c1)OCO2</smiles>

(2E,4E)-5-(2H-1,3-benzodioxol-5-yl)- $N$-(2-methylpropyl)penta-2,4-dienamide<smiles>O=C(/C=C/C=C/CCc1ccc2c(c1)OCO2)N1CCCCC1</smiles>

(2E,4E)-7-(2H-1,3-benzodioxol-5-yl)-1-(piperidin-1-yl)hepta-2,4-dien-1-one 


\section{Experimental}

\subsection{Preparation of black pepper extract}

Black pepper seeds were completely dried, powdered and boiled in $50 \%$ hydrochloric acid for $6 \mathrm{~h}$ at reflux temperature. It was then cooled to room temperature and $\mathrm{pH}$ was adjusted to 7 using $10 \%$ sodium bicarbonate solution. It was kept for $24 \mathrm{~h}$ at room temperature [4]. The solution extracted was then filtered and concentrated until the water from the extract evaporates. Various concentrations have been prepared by using the extract. Laboratory reagent grade $\mathrm{HCl}$ and deionized water were used to prepare test solutions for all experiments [5].

\subsection{Chemical Constituents of Mild Steel}

Experiments were performed on mild steel having the following percentage composition (wt \%): $0.19 \mathrm{C}, 0.64 \mathrm{Mn}, 0.26 \mathrm{Si}, 0.27 \mathrm{Cu}, 0.09 \mathrm{Ni}, 0.08 \mathrm{Cr}, 0.06 \mathrm{P}, 0.05 \mathrm{~S}, 0.02 \mathrm{Mo}$, and $98.34 \mathrm{Fe}[6]$.

\subsection{Specimen preparation}

The working surface was polished with various grades of emery-paper with different grain sizes 200, 400, 600, 800, and 1000, washed with distilled water, degreased with acetone, and dried at room temperature [7]. Weight loss analysis was performed using mild steel samples of dimension $1 \mathrm{~cm}$ x $1 \mathrm{~cm}$ x $0.25 \mathrm{~cm}$. For scanning electron microscope (SEM) investigation specimens of dimension $1 \times 1 \mathrm{~cm}$ were used.

\subsection{Weight- loss technique}

This technique was accomplished to study the impact of the addition of various concentrations of inhibitor on the mild steel corrosion in $1.5 \mathrm{M}$ nitric acid at ambient temperature. In the absence and presence of various inhibitor concentrations at studied temperatures, the metal to be tested was polished, weighed, and immersed for $1 \mathrm{~h}$ in a 250 $\mathrm{mL}$ electrolyte solution [8]. The metal was removed after $1 \mathrm{~h}$ of immersion, washed with distilled water, and dried for $5 \mathrm{~min}$ in a hot air oven. Afterward, the metal was weighed using a digital balance.

The inhibition efficiency (\%) was calculated by,

$\operatorname{IE}(\%)=\frac{W_{o}-W_{i}}{W_{o}} \times 100$

Where $W_{\mathrm{o}}$ is the weight loss of mild steel in the absence of the inhibitor and $W_{\mathrm{i}}$ is the weight loss of mild steel in the presence of the inhibitor. 


\section{Results and Discussion}

\subsection{Weight- loss measurements}

The values of percentage inhibition efficiency (\% I.E.) retrieved from weight loss analyses at different concentrations of black pepper extract at $28{ }^{\circ} \mathrm{C}$ are compiled in Table 1. Corrosion rate (CR) was calculated by the following equation.

$\mathrm{CR}(\mathrm{mmpy})=\frac{87.6 \times W}{D \times A \times T}$

Where $W$ is the weight loss, $D$ is the density, $T$ is the time of immersion and $A$ is the area of the specimen respectively. The inhibition capability increases with the rise in the concentration of the inhibitor up to the optimum level [9], consequently, it was identified to decrease slightly, which is due to the interaction between adsorbed molecules at the sites [10]. The extent of inhibition depends on the nature and concentration of the inhibitor. The corrosion rate decreases with an increase in the concentration of the inhibitor. It was noticed that extract prevents the corrosion of mild steel in nitric acid solution at all the concentrations used in this research viz. $50 \mathrm{ppm}$ to $200 \mathrm{ppm}$. It was detected that inhibition efficiency increases with increasing concentration of inhibitor and maximum efficiency were observed at $200 \mathrm{ppm}$ [11].

Table1. Corrosion specifications for mild steel in $1.5 \mathrm{M}$ nitric acid in absence and presence of different concentrations of black pepper extract from weight loss evaluations at $28^{\circ} \mathrm{C}$.

\begin{tabular}{llll}
\hline Inhibitor & $\begin{array}{l}\text { Concentration } \\
(\mathrm{ppm})\end{array}$ & $\begin{array}{l}\text { Weight loss } \\
(\mathrm{mg})\end{array}$ & $\begin{array}{l}\text { Inhibition efficiency } \\
(\%)\end{array}$ \\
\hline 1.5 M Nitric acid & 0 & 1.478 & - \\
\hline & 50 & 0.737 & 50.135 \\
Black pepper & 100 & 0.602 & 59.269 \\
extract & 150 & 0.325 & 78.011 \\
\hline
\end{tabular}

\subsection{Surface analysis}

SEM micrographs of the mild steel surface disclosed to acidic medium revealed that the surface was blanketed by corrosion products primarily subsisting of oxides and chlorides [12]. The layer is widely porous in nature and thus anodic dissolution of metals takes place at pores. The presence of the inhibitor results in the development of non-porous and compact surface film, which effectively controls the dissolution of Mild Steel alloys and prevents the alloy surface against corrosion [13].

The SEM picture (Fig. 1A) shows that the surface is extremely damaged in the absence of the inhibitor while (Fig. 1B) exhibits a development of a film by the black pepper constituent on the metal surface which may be efficient for the corrosion inhibition. 


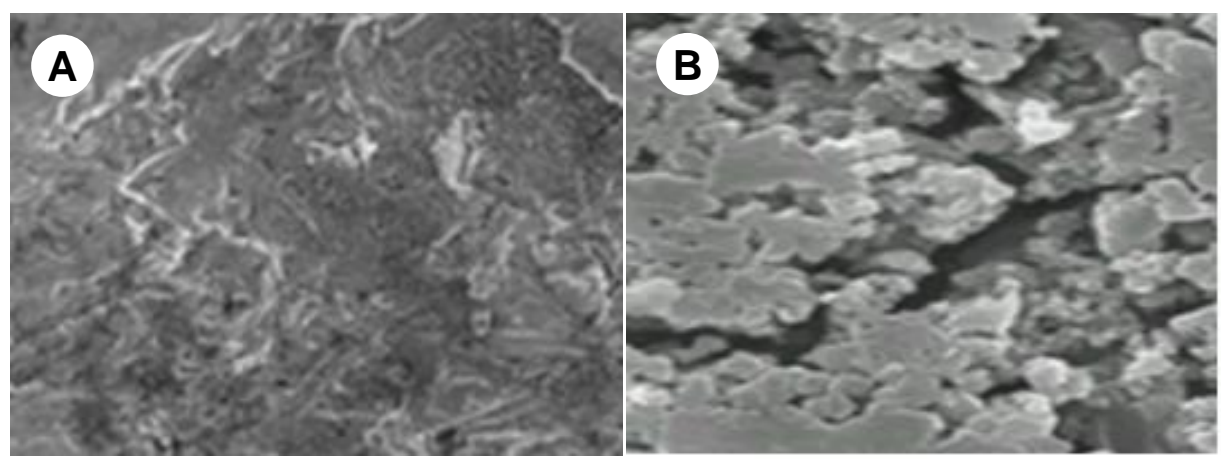

Fig. 1. SEM micrographs of mild steel (A) in $1.5 \mathrm{M} \mathrm{HNO}_{3}$ medium (B) with black pepper extract (200 ppm).

\subsection{FTIR analysis}

Fig. 2 shows the aromatic $\mathrm{C}-\mathrm{H}$ stretching at $3000 \mathrm{~cm}^{-1}$; symmetric and asymmetric stretching of $\mathrm{C}=\mathrm{C}$ (diene) at $1635,1608 \mathrm{~cm}^{-1}$; aromatic stretching of $\mathrm{C}=\mathrm{C}$ (benzene ring) at $1608,1580,1495 \mathrm{~cm}^{-1}$ and stretching of $-\mathrm{CO}-\mathrm{N}$ at $1635 \mathrm{~cm}^{-1}$, respectively. For methylenedioxy group, the asymmetric and symmetric $\mathrm{CH}_{2}$ stretching, aliphatic $\mathrm{C}-\mathrm{H}$ stretching at $2925,2840 \mathrm{~cm}^{-1} ; \mathrm{CH}_{2}$ bending at $1450 \mathrm{~cm}^{-1}$; asymmetrical stretching $=\mathrm{C}-\mathrm{O}-$ $\mathrm{C}$ at $1250,1190 \mathrm{~cm}^{-1}$; symmetrical stretching $=\mathrm{C}-\mathrm{O}-\mathrm{C}$ at $1030 \mathrm{~cm}^{-1} ; \mathrm{C}-\mathrm{O}$ stretching at 930 $\mathrm{cm}^{-1}$; in-plane bending of phenyl C-H at $1132 \mathrm{~cm}^{-1} ; \mathrm{C}-\mathrm{H}$ bending of trans $-\mathrm{CH}=\mathrm{CH}-$ at 995 $\mathrm{cm}^{-1}$ and out-of-plane $\mathrm{C}-\mathrm{H}$ bending 1,2,4-trisubstituted phenyl at $850,830,805 \mathrm{~cm}^{-1}$, respectively.

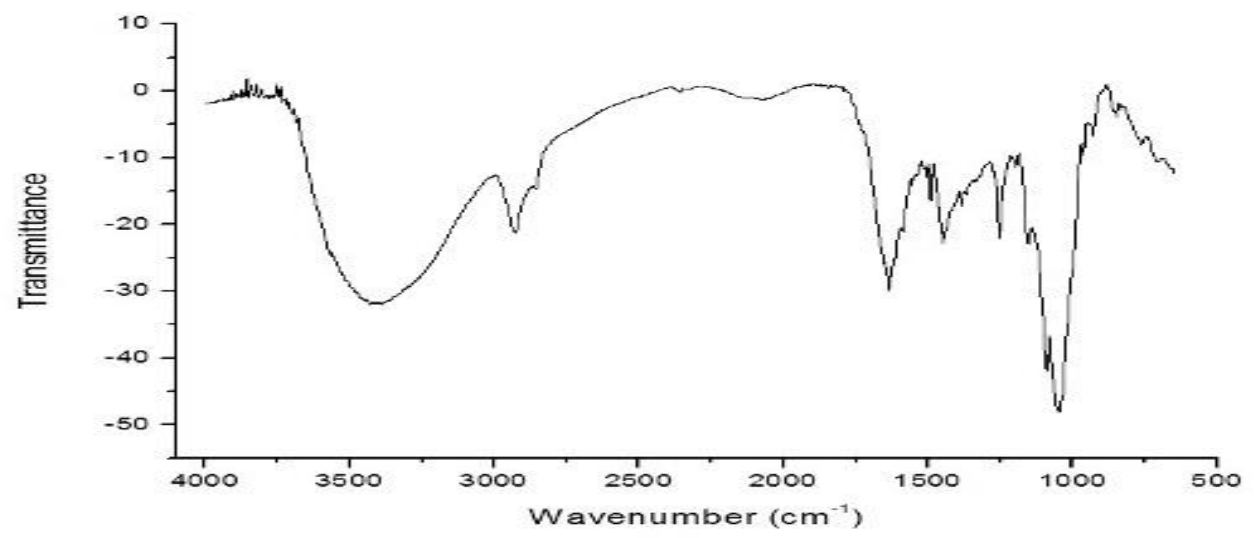

Fig. 2. FTIR of black pepper extract.

\section{Conclusion}

The weight-loss method shows that the maximum inhibition efficiency was $96.14 \%$ at 28 ${ }^{\circ} \mathrm{C}$ and a concentration of $200 \mathrm{ppm}$. SEM micrographs proved that the inhibition is due to 
the development of an insoluble stable film through the process of complexation of the organic molecules on the metal surface. Investigations of the SEM images show that there is severe damage to the mild steel surface in the absence of inhibitor. There are fewer pits and cracks observed in the inhibited surface. FTIR analysis confirms that the inhibited surface is covered by Piper nigrum. The result of the present analysis indicates that mild steel can be occupied as a construction material in the marine environment. Investigations on the introduction of effective eco-friendly inhibitors without affecting the service life of the material should be a welcome approach.

\section{Acknowledgment}

This work was supported by the Department of Chemistry, Anna University, MIT Campus. Thanks to all the Staff members for the support.

\section{References}

1. A. Gruca and M. G. Stachura, Inz. Mat. 227, 19 (2019).

2. M. A. Quraishi, D. K. Yadav, and I. Ahamad, The Open Corros. J. 2, 56 (2009). https://doi.org/10.2174/1876503300902010056

3. D. Ladha, N. Shah, S. Thakur, M. Lone, and P. Jha, Pig. Res. Technol. 45, 106 (2016). https://doi.org/10.1108/PRT-10-2014-0086

4. M. Sivaraju, K. Kannan, and M. Shankarraj, Asian J. Chem. 20, 6103 (2008).

5. M. Dahmani, A. E. Touhami, S. S. A. Deyab, B. Hammouti, and A. Bouyanzer, Int. J. Electrochem. Sci. 5, 1060 (2010).

6. P. B. Raja and M. G. Sethuraman, Mat. Let. 62, 2977 (2008). https://doi.org/10.1016/j.matlet.2008.01.087

7. M. Dahmani, S. S. Al-Deyab, A. Et-Touhami, B. Hammouti, A. Bouyanzer, R. Salghi, and A. ElMejdoubi, Int. J. Electrochem. Sci. 7, 2513 (2012).

8. B. Hammouti, M. Dahmani, A.Yahyi, A. Ettouhami, M. Messali, A. Asehraou, A. Bouyanzer, I. Warad, and R. Touzani, Arab. J. Chem. Environ. Res. 6, 12 (2019).

9. C. Verma, E. E. Ebenso, I.Bahadur, and M. A. Quraishi, J. Mol. Liq. 266, 577 (2018). https://doi.org/10.1016/j.molliq.2018.06.110

10. M. E. Belghiti, S. Echihi, A. Mahsoune, Y. Karzazi, A. Aboulmouhajir, A. Dafali, and I. Bahadur, J. Mol. Liq. 261, 62 (2018). https://doi.org/10.1016/j.molliq.2018.03.127

11. E. Alibakhshi, M. Ramezanzadeh, G. Bahlakeh, B. Ramezanzadeh, M. Mahdavian, and M. Motamedi, J. Mol. Liq. 255, 185 (2018). https://doi.org/10.1016/j.molliq.2018.01.144

12. K. Xhanari, M. Finsgar, M. K. Hrncic, U. Maver, Z. Knez, and B. Seiti, RSC Adv. 7, 27299 (2017). https://doi.org/10.1039/c7ra03944a

13. B. Raja and M. G. Sethuraman, Mater. Lett. 62, 113 (2008).

https://doi.org/10.1016/j.matlet.2007.04.079 